\title{
The burden of lung disease in Europe: why a European White Book on lung disease?
}

\author{
R. Loddenkemper*, G.J. Gibson", Y. Sibille
}

On November 25, 2003, the European Lung White Book was presented officially to members of the European Parliament in Brussels, Belgium. This project was initiated 5 yrs ago when the Executive Committee of the European Respiratory Society (ERS) decided to inform the European Community and European Union (EU) decision-makers about the increasing burden of lung disease and the importance of lung health. The European Lung White Book then became part of a global public health awareness campaign supported by the European Lung Foundation: the "Breath of Life" campaign. The main objectives of this White Book, which is the first document to include epidemiological data collected from all European countries on the full spectrum of respiratory disorders are as follows:

1) To raise public awareness of the importance of lung diseases and measures necessary to counter their increase. Major respiratory disorders, pneumonia (third), chronic obstructive pulmonary disease (COPD; fifth), tuberculosis (TB; sixth) and lung cancer (ninth) currently rank among the 10 leading causes of death worldwide. Projections for 2010 even predict an increase in mortality due to COPD, TB and lung cancer, with COPD becoming the third leading cause of death worldwide. In addition, asthma is currently the most frequent chronic disease affecting children, while cystic fibrosis ranks first among genetic disorders in terms of prevalence.

2) To provide the most thorough descriptions possible of the current state of lung disease and respiratory medicine in Europe.

3) To show how national variations in all areas of respiratory medicine affect patient care and cost of treatment.

4) To promote the implementation of common disease definitions, treatment standards and epidemiological surveillance across Europe.

The book is divided into six sections. The first includes an overview of the burden of lung disease in Europe and its economic impact. Section two is dedicated to the major respiratory diseases, which are defined in terms of incidence, prevalence, mortality, cost of care and future requirements to improve both research and patient care. The third section considers major risk factors, in particular tobacco smoking, environmental and occupational agents. The fourth part focuses on special fields of care in respiratory medicine (paediatric respiratory medicine, thoracic surgery, intensive

\footnotetext{
*Chief Editor, European Lung White Book, "President 2002-2003, European Respiratory Society and Chair, European Lung Foundation.

Correspondence: Y. Sibille, Service de Pneumologie, Cliniques Universitaires, de Mont-Godinne, B-5530 Yvoir, Belgium. Fax: 3281423352. E-mail: sibille@mblg.ucl.ac.be

To preorder copies of the European Lung White Book, please send an e-mail to admin@ersj.org.uk
}

care medicine, rehabilitation and the roles of healthcare professionals). This is followed by a section on training, teaching and research in respiratory medicine across Europe. Finally, part six provides a list of useful contacts; international and national scientific societies and European patient organisations.

The publication of this report was only made possible with the help of a large number of experts from all over Europe. More than 50 contributors (section editors, authors and reviewers) participated in the writing of this publication. The data presented in the European Lung White Book were generated though several sources including the European Community, the World Health Organization (WHO), the Organization for Economic Cooperation and Development (OECD), and national statistics collected with the help of ERS national delegates. As stated in the introduction of the book, despite the variety of sources, data are often incomplete or missing for several countries or parts of Europe, showing the urgent need for pan-European systems of epidemiological surveillance.

The European Lung White Book will be produced in two formats; the full version is aimed primarily at the medical community. This should serve as a reference publication on the state of lung disease and respiratory medicine in Europe. Another shorter summary version will be used to raise awareness of the burden of respiratory disease among decision-makers, the media and patient organisations. This summary version should be used to alert the public to the necessity to promote better respiratory care in Europe and better understanding of the dramatic impact of diseases that are not well known, such as COPD.

Both G.H. Brundtland, Director General of the WHO (1998-2003) and D. Byrne, European Commissioner for Health and Consumer Protection, have kindly written forewords, testifying to the importance of this book and to the increasing recognition by both the EU and the WHO of the burden of lung disease.

This first European Lung White Book is not an end, but rather a beginning. By informing the public and decisionmakers about the importance of lung disorders, it is hoped that more attention will be drawn to lung health and respiratory medicine, and that this will also result in better funding of respiratory research in Europe. Moreover, the presence of incomplete or missing data stresses the need for more epidemiological studies to be carried out across Europe using common and well-established methods to validate the data collected.

Finally, it is hoped that European Respiratory Society members will use this document to distribute information on lung health all over Europe and in their respective countries, to sensitise politicians, the media and the public to the importance of taking measures aimed at countering the progression of respiratory disease. 